\title{
Are we equipped with serving the right care? Implications for program responses regarding gender-based violence
}

Khaing Nwe Tin ( $\sim$ khaingnwetin@gmail.com )

Myanmar Ministry of Health and Sports

Myitzu Tin Oung

Myanmar Ministry of Health and Sports

\section{Su Su Yin}

Myanmar Ministry of Health and Sports

Kyaw Ko Ko Htet

Myanmar Ministry of Health and Sports

Kyaw Thu Hein

Myanmar Ministry of Health and Sports

Hla Mya Thway Einda

Myanmar Ministry of Health and Sports

Kyu Kyu Than

Burnet Institute

Research article

Keywords: Gender Based Violence, GBV management, readiness of health sector, Myanmar

Posted Date: November 4th, 2019

DOI: https://doi.org/10.21203/rs.2.16705/v1

License: (c) (i) This work is licensed under a Creative Commons Attribution 4.0 International License. Read Full License 


\section{Abstract}

Background Globally, 35\% of women have experienced gender-based violence (GBV) which seriously affects all aspects of women's health. While health sector must play a key role in response, there are many barriers for GBV survivors to access health services, especially in developing countries including Myanmar. Limitations of health sector in provision of quality services to GBV survivors, healthcare providers' knowledge, attitude, experience and service availability and readiness, should be explored as an initial step for the improvement of health care response to GBV survivors.

Methods This study was a cross-sectional descriptive study conducted in four purposively selected townships with higher number GBV cases. Face-to-face interviews were done to all health care providers $(n=233)$ from public health facilities using a structured questionnaire. The findings were described as frequency and percentage for categorical data and mean and standard deviation for continuous data.

Results Lady Health Visitors and Midwives were mainly involved (88.0\%). About two-thirds had heard GBV without probing. Types of violence they mostly described were physical (81.1\%) and sexual violence (8.5\%). One-third wanted women to be patient to their partners' violence to maintain family ties. Nearly two-third assumed conflict between husband and wife was not a matter that someone should involve. About $70 \%$ had given care to GBV survivors and they provided only injury treatment (76.1\%). A quarter of them experienced sexual violence cases, but only $4.9 \%$ and $1.2 \%$ provided emergency contraception and Sexually Transmitted Infection treatment. Although nearly two third mentioned about psychological counseling in GBV management, only $20 \%$ provided counseling services to survivors. Absence of standard GBV management guideline, trained and skilled staff for GBV and counseling room at health facilities were issues mostly stated by the respondents.

Conclusions Inadequate knowledge, misconceptions and unfavorable attitudes of GBV among health care providers might deter the effectiveness of GBV management at the health sector. In addition, poor management practice together with no standard management guideline, limited skilled staff, inadequate drug supplies and absence of counseling facilities indicated insufficient readiness to provide quality health care responses to GBV surviours in Myanmar.

\section{Background}

Gender-Based Violence (GBV) occurs as a cause and consequence of gender inequities, including a range of violence acts mainly committed by males against females, within the context of women and girls subordinate status in society [1]. There are different forms of GBV that includes domestic violence (DV) by an intra-family member; intimate partner violence (IPV) including physical, sexual or psychological harm by a current or former partner or spouse; sexual violence (SV) including rape, sexual abuse, forced pregnancies and prostitution; traditional harmful practices including female genital mutilation (FGM), honor killing and dowry related violence; and human trafficking [2]. 
GBV is the most widespread of all human rights violations and a global public health problem affecting all socio-economic and cultural groups throughout the world. Worldwide, $35 \%$ of women have experienced physical and/or sexual violence from intimate partners or non-partners. According to the studies from different countries, most of the violence is IPV. Worldwide, $15-71 \%$ of women aged 15 to 49 years have experienced sexual or physical violence conflicted by her intimate partner some point in her life and one in three women have a risk to experience IPV in her life time. In Southeast Asia, lifetime prevalence of physical or/and sexual violence by intimate partner among ever-partnered women is $37.7 \%$ [3].

According to Myanmar Demographic Health Survey 2015, in Myanmar, 15\% of women have experienced physical violence from husband or anyone else since age 15 and divorced/separated/widowed women and married women are more likely to experience physical violence than never-married women (33\%, $17 \%$ and $9 \%$ respectively). In terms of IPV, $21 \%$ of ever-married women have experienced spousal violence and physical violence is the most common type of IPV (15\%) and it was followed by emotional violence (14\%) and by sexual violence (3\%). Among women who have experienced physical or sexual violence committed by anyone, only $22 \%$ sought help to stop violence [4].

GBV seriously affects all aspects of women's health-physical, sexual and reproductive, mental and behavioral health. Health consequences of GBV can be immediate and acute as well as long lasting and chronic. Indeed, negative health consequences may persist even long after the violence has stopped. The more severe the level of violence, the greater the impact will be on women's health. Women who have been physically or sexually abused by their partners are more than twice as likely to have an abortion, almost twice as likely to experience depression, and in some regions, 1.5 times more likely to acquire HIV, as compared to women who have not experienced partner violence [5].

Considering serious health risks faced by women and their families, the health sector must play a greater role in responding to physical and sexual violence against women. However, there are many barriers and challenges for GBV survivors to inform and access health services in Myanmar. At the same time, health facilities have some limitations to prescribe proper treatment and services to prevent GBV related health outcomes. In addition, there is an absence of a standard guideline and proper training for health care providers of public sectors to handle GBV cases efficiently. The limitations and challenges of the medical professional to provide medical services for GBV victims should be studied to prevent health consequences of GBV.

This study assessed knowledge, perception and experiences of health care providers regarding GBV and its management and identified readiness of public health facilities for provision of health services to GBV survivors. The results of the study can help program managers understand how many health care providers know about GBV and its management, what are their perceptions on GBV and GBV survivors, and what resources are lacking in the health facilities for effective management of GBV. The findings can be applied for future guideline development for GBV management and for provision of trainings to health 
care professionals from public health sector. In addition, the information can be documented as a baseline and the changes over time can be measured after providing trainings.

\section{Materials And Methods}

This study was a cross-sectional descriptive study. It was conducted in four purposively selected townships where there were high number of GBV cases according to information from Regional Health Department, Social Welfare Department, local and international organizations that are working for GBV, i.e. Hlaing Thar Yar and Kawhmu in Yangon Region and Singu and Patheingyi in Mandalay Region. Data were collected from face-to-face interviews with all healthcare providers who were available at the time of data collection $(n=233)$ using a structured questionnaire. The healthcare providers involved in the study were medical officers, hospital nurses, lady health visitors (LHV) and midwives (MW) from selected townships. Data entry and data analysis was performed using SPSS version 20 . The findings were described as frequency and percentage for categorical data and mean and standard deviation for continuous data. The study was conducted with the ethical approval of the Ethics Review Committee, Department of Medical Research. Data collection was done after obtaining voluntary informed consents from all participants.

\section{Results}

The respondents were health care providers of public sectors from Hlaing Tharyar (13.7\%) and Kawhmu townships (24.0\%) of Yangon Region and Patheingyi (27.0\%) and Singu townships (35.2\%) of Mandalay Region. The majority of healthcare providers were from rural health centers (RHCs) $(73.8 \%)$ and the remaining was from Township Hospitals (6.4\%) and Station Hospitals (6.9\%), Maternal and Child Health $(\mathrm{MCH})$ clinics (4.3\%) and Urban Health Center (UHC) (7.7\%).

\section{Background information of respondents}

The basic health staff, including Lady Health Visitors (LHV) and Midwives (MW), was mainly involved in the study, representing $88.0 \%$ of the total while the remaining was medical doctors, health assistants (HA) and nurses. Majority of healthcare providers was female (96.1\%). The average of total service years of participants was $12.7 \pm 9.1$ years and those who had more than 10 years working experience was $57.9 \%$.

\section{$<$ Table 1 here>}

\section{Knowledge and perception of healthcare providers on GBV related issues}


About two-thirds of healthcare providers had heard the term of "gender-based violence" without probing and the rest noticed only after probing by interviewers. The common types of GBV that they have heard were physical and sexual violence, $81.1 \%$ and $78.5 \%$ respectively. Only $39.1 \%$ and $22.7 \%$ of health care providers had heard on emotional/psychological violence and economic resources/assets related violence respectively.

\section{$<$ Table 2 here $>$}

More than two-third of respondents considered GBV as a common problem by providing agreement on the statement "one of three women suffers GBV worldwide" where the rest responded that the GBV cases were not as common as the statement said. Almost all of healthcare providers (96.1\%) agreed women were suffering GBV more than male while others believed both men and women could be the victims of GBV.

Most of healthcare providers ( $80 \%$ and above) regarded the violence against girls/women conflicted by their male partners as GBV, but lesser number of respondents ( $70 \%$ and below) assumed it as GBV if the violence was conflicted by a family member. Many healthcare providers $(81.1 \%)$ responded that young girls were the vulnerable persons to GBV and $57.9 \%$ believed children were vulnerable too. Those who use drugs and alcoholics were the mostly cited potential perpetrators of GBV by healthcare providers $(73.4 \%)$.

\section{<Figure 1 here>}

Identifying the perception of healthcare providers on IPV showed there were some healthcare providers still had misconceptions about GBV. One-third of healthcare providers (36.5\%) wanted women to be patient with violence from their intimate partners to maintain a family ties where the remaining responded that women should not be patient to any violence. Nearly two-third of them assumed the conflict between a husband and a wife is not a matter that someone should involve. It seems many healthcare providers accepted intimate partner violence to a certain extent.

\section{<Figure 2 here>}

To the question about health-related consequences of GBV which was not specified any type of GBV, most of the healthcare providers could name many consequences. Psychological problem was the most commonly provided response by the healthcare providers, accounting for $70.8 \%$, followed by injuries $(47.6 \%)$ and unwanted pregnancy (35.2\%). Among them, 31.8\% answered suicide as one of the health consequences of GBV.

\section{$<$ Figure 3 here>}


To the question of what healthcare providers should do when GBV survivors come to their clinic, provision of counseling was the highest number of responses provided by the healthcare providers $(65.2 \%)$ and it was followed by treatment of injuries (51.5\%). Only few of them talked about sexual assault examination (6.9\%), sexual assault care (9.4\%), and documentation (7.7\%). Although a high percentage of healthcare providers named psychological problems as a health-related consequence, only $17 \%$ mentioned about mental health assessment and mental health care to GBV survivors.

\section{Experiences of healthcare providers in provision of GBV care}

Among 233 participants, 70\% (163) reported that they had ever provided care to GBV survivors. Most GBV survivors who came to health facilities were over 20 years of age (62.7\%). Most of the victims came to health facilities with physical violence (75.6\%), and approximately a quarter of GBV cases were sexual violence. According to the healthcare providers, the cases reached to health facilities were mostly conflicted by the survivors' intimate partners $(73.8 \%)$ and a third of violence cases were done by the strangers $(28.7 \%)$.

\section{$<$ Table 3 here $>$}

The care that healthcare providers provided to GBV survivors was mostly injury treatment $(76.1 \%)$. Nearly half of healthcare providers gave medicines to survivors. It was found the proportion of healthcare providers who referred cases to somewhere else was not small $(40.5 \%)$ and the place they mostly referred to was township hospitals. A quarter of healthcare providers said sexual violence cases reached to their health facilities, but only $4.9 \%$ and $1.2 \%$ of healthcare providers had provided emergency contraception and Sexually Transmitted Infection (STI) treatment. The findings indicated that many sexual violence cases were mostly referred to township hospitals.

While more than half of healthcare providers talked about provision of counselling to GBV survivors in the knowledge and perception section, only one-fifth of respondents said that they provided counseling service to the survivors who came to their health facilities.

\section{$<$ Figure 4 here>}

\section{Readiness of care for GBV survivors at health facility}

Concerning with readiness in health facilities for provision of care to GBV survivors, almost all of healthcare providers (more than $90 \%$ ) said there were no standard management guideline, trained and 
skilled staff, trained medico-social worker and counseling room at the health facilities. However, only half of them responded that there were no adequate medicinal supplies for GBV management.

\section{$<$ Table 4 here $>$}

\section{Discussion}

Almost all of respondents involved in the study were nurses, lady health visitors and midwives who were women. Thus, the findings could not highlight the perspectives of men, but the findings could represent the health care providers' view from the health sector where women are contributed to the dominant portion. It seems that knowledge and perception of men is also important in planning and implementation of programs and responses related to GBV, involvement of small portion of men can be taken as a limitation of this study. In one study in Brazil which investigated knowledge and attitude of healthcare providers towards GBV, perspectives from both male and female healthcare workers were explored and the results showed no difference between men and women regarding knowledge but had differences in some attitudinal questions [6].

According to the findings, it can be concluded that healthcare providers possessed general knowledge of GBV, but they did not have adequate knowledge to provide quality care. Most of them had heard only two types of GBV, physical and sexual violence, and they viewed only those two types were related to the health sector. With that knowledge, nearly $100 \%$ of respondents agreed physical and sexual violence conflicted by male partners as GBV whereas lesser number of respondents perceived humiliation and verbal abuse conflicted by intimate partners or family members as GBV.

There were also misconceptions of GBV among healthcare providers. For instance, more than half of health care providers assumed they should not involve in the conflict between husbands and wives and a third of healthcare providers preferred women to be patient with violence from their intimate partners to maintain a family ties. Those unfavorable attitudes of health care providers might deter them to be able to provide effective management to GBV cases, and then will effect on health seeking behaviour of the survivors.

They were also unaware of certain important aspects of GBV management, such as provision of STI/HIV prophylaxis, emergency contraceptive pills for prevention of pregnancy and referral to social support. Only one fifth of health care providers mentioned mental health assessment and mental health care as components of GBV management. At the same time, although nearly two third of them were aware of the need of psychological counseling to survivors, only $20 \%$ said they provided counseling services to survivors who came to the health center. Very few number of respondents stated documentation as one of the components in GBV management. The findings highlighted that healthcare providers need ongoing trainings on the subject, its importance and management to improve the quality of care. 
To enable health care workers to deliver better quality care to GBV survivors, management guideline is an essential tool for building the capacity of healthcare providers. Some healthcare providers reported that they do not know clearly about how to manage GBV cases and almost all respondents answered the facility did not have any guideline for GBV management. This finding indicated all health facilities should be provided a GBV management guideline with Standard Operating Procedures (SOPs).

More than two-third of health care providers had experiences of delivering health services to GBV survivors and most of the cases were physical violence and it was followed by sexual violence. It means that GBV is not uncommon in the study setting. Thus, health facilities should be ready to provide appropriate care to GBV cases, especially for physical and sexual violence. However, the health facilities did not have enough supplies of medicines that needed in the management of GBV, especially for sexual violence, e.g. emergency pills and treatment for post-exposure prophylaxis. Provision of adequate medicine supply to all levels of health facilities can improve utilization of health services by survivors.

Lack of trained and skilled staff for GBV management, including provision of counseling services, at health facilities would also hinder to deliver quality GBV care. To make it effective, the medico-social workers should be assigned and trained to be able to identify psychosocial problems of the survivors, to communicate survivors with non-judgmental approach, to handle disclosure of GBV, to protect safety, confidentiality and privacy of survivors and to provide psychosocial supports that they really need.

\section{Conclusions}

This study highlights the inadequate knowledge, misconceptions and unfavorable attitudes on GBV among health care providers from public health facilities. These might deter on effective management and health seeking behaviour of the survivours to access the quality health care responses. Poor awareness of GBV management; provision of STI/HIV prophylaxis, prevention of unwanted pregnancy and referral to social support, no standard management guideline, limited skilled staff, inadequate drug supplies and counseling facilities highlighted insufficient readiness to provide quality health care responses to GBV surviours in Myanmar. Therefore, programs need to tackle these limitations and challenges to be ready for provision of quality, comprehensive health care responses to GBV surviours aiming to protect from negative consequences of GBV.

\section{Abbreviations}

DV: Domestic Violence, GBV: Gender Based Violence, HA: Health Assistant, IPV: Intimate Partner Violence, LHV: Lady Health Visitor, MCH: Maternal and Child Health, MW: Midwives, RHC: Rural Health Center, SOP: Standard Operating Procedure, STI: Sexually Transmitted Infection, UHC: Urban Health Center

\section{Declarations}

\section{Ethics approval and consent to participate}


Ethics approval for conducting this study was obtained from the Ethics Review Committee of the Department of Medical Research, Ministry of Health and Sports, Myanmar. Written informed consent was obtained from each and every participant.

\section{Consent for publication}

Not applicable.

\section{Availability of data and materials}

The datasets used and/or analyzed during the current study are available from the corresponding author on reasonable request.

\section{Competing interests}

The authors declare that they have no competing interests.

\section{Funding}

This study was conducted with the funding support of WHO country work plan (2016-17).

\section{Authors' contributions}

The work was conceived and designed by KNT, MZTO, SSY and KKT. KNT, MZTO, SSY, KKT and HMTED involved in conceptualization. KNT, MZTO, KKKH and KTH collected the data. MZTO, KKKH and KTH analyzed the data. MZTO and KKKH contributed to writing the paper and manuscript. KNT helped to edit and finalize the manuscript. All authors read and approved the final manuscript.

\section{Acknowledgements}

We thank the Department of Public Health, Ministry of Health and Sports, Myanmar for allowing conducting this research and the World Health Organization for providing financial support to conduct this research. We also thank all healthcare providers from Hlaing Thar Yar, Kawhmu, Singu and Patheingyi townships, who participated in this research and provided any assistance in conducting this study.

\section{Authors' information (optional)}

\section{References}


1. United Nations Economic and Social Affairs (2015). The World's Women 2015, Trends and Statistics, p. 159. - See more at: http://www.unwomen.org/en/what-we-do/ending-violence-againstwomen/facts-and-figures\#sthash.EV19n8s1.dpuf

2. World Health Organization, Department of Reproductive Health and Research (2013). Global and regional estimates of violence against women: prevalence and health effects of intimate partner violence and non-partner sexual violence, p.2.

3. Facts and figures: Ending violence against women http://www.unwomen.org/en/what-we-do/endingviolence-against-women/facts-and-figures\#notes

4. Ministry of Health and Sports (MoHS) and ICF, 2017. Myanmar Demographic and Health Survey 2015-16. Nay Pyi Taw, Myanmar and Rockville, Maryland USA: Ministry of Health and Sports and ICF.

5. For individual country information, see The World's Women 2015, Trends and Statistics, Chapter 6, Violence against Women, United Nations Department of Economic and Social Affairs, 2015. - See more at: http://www.unwomen.org/en/what-we-do/ending-violence-against-women/facts-andfigures\#sthash.EV19n8s1.dpuf

6. Vieira EM, Perdona GCS, Almeida AM, Nakano AMS, Santos MA, Daltoso D, et al. Knowledge and attitudes of healthcare workers towards gender based violence, Rev Bras Epidemiol, 2009; 12(4): 1-12

\section{Tables}

Table 1 Background characteristics of health care providers $(n=233)$ 


Characteristics of healthcare providers Number Percentage

\begin{tabular}{|c|c|c|}
\hline \multicolumn{3}{|l|}{ Designation } \\
\hline Medical doctors & 4 & (1.8) \\
\hline Nurses & 24 & $(10.3)$ \\
\hline Basic Health Staff & 205 & $(88.0)$ \\
\hline \multicolumn{3}{|l|}{ Age (years) } \\
\hline$<30$ & 44 & $(18.9)$ \\
\hline $30-39$ & 96 & $(41.2)$ \\
\hline $40-49$ & 60 & $(25.8)$ \\
\hline$\geq 50$ & 33 & $(14.2)$ \\
\hline Mean \pm SD (range) & \multicolumn{2}{|c|}{$38.2 \pm 9.2$ year ( 21 to 60$)$} \\
\hline \multicolumn{3}{|l|}{ Gender } \\
\hline Male & 9 & (3.9) \\
\hline Female & 224 & $(96.1)$ \\
\hline \multicolumn{3}{|l|}{ Total service years } \\
\hline$<10$ & 98 & $(42.1)$ \\
\hline $10-19$ & 89 & $(38.2)$ \\
\hline $20-29$ & 31 & $(13.3)$ \\
\hline$\geq 30$ & 15 & $(6.4)$ \\
\hline Mean \pm SD (range) & \multicolumn{2}{|c|}{$12.7 \pm 9.1$ year $(<1$ to 36$)$} \\
\hline \multicolumn{3}{|c|}{ Service years at the current health facility } \\
\hline$<10$ & 161 & $(69.1)$ \\
\hline $10-19$ & 57 & $(24.5)$ \\
\hline $20-29$ & 12 & $(5.2)$ \\
\hline$\geq 30$ & 3 & $(1.3)$ \\
\hline Mean \pm SD (range) & \multicolumn{2}{|c|}{$7.2 \pm 7$ year $(<1$ to 33$)$} \\
\hline
\end{tabular}

Nurses: Staff nurse and trained nurse who are working at the station and township hospitals 
Table 2 Knowledge and perception of healthcare providers on GBV related issues $(n=233)$ 


\section{Responded as "Yes" to the statements:}

One of three women suffers GBV worldwide

172

(73.8)

Women are suffering GBV more than male

224

$(96.1)$

It is called $G B V$ if a girl/woman is

- $\quad$ humiliated or verbally abused by her male partner

186

- $\quad$ physically abused by her male partner

226

$(97.0)$

- $\quad$ sexually abused by her male partner

231

(99.1)

- $\quad$ humiliated or verbally abused by a male family member

111

$(47.6)$

- physically abused by a male family member

162

(69.5)

\section{Vulnerable persons for GBV}

Children

Young girls

Less educated girls/women

Poor girls/women

Mentally ill girls/women

Homeless girls/women

Drug user or alcoholics

Women in the conflicted areas
135

189

56

78

30

26

8

3
(57.9)

(24.0)

\section{Potential perpetrators in GBV}

Rich men 
Drug users or alcoholics

Note: Multiple responses were allowed

Table 3 Experiences of healthcare providers on provision of care to GBV survivors $(n=163)$ 


\begin{tabular}{|c|c|c|}
\hline Characteristics of survivors & Frequency & Percentage \\
\hline \multicolumn{3}{|l|}{ Age range } \\
\hline Under 12 & 35 & 15.0 \\
\hline 12 to 20 & 41 & 17.6 \\
\hline Over 20 & 146 & 62.7 \\
\hline \multicolumn{3}{|l|}{ Type of violence } \\
\hline Physical violence & 124 & $(75.6)$ \\
\hline Sexual violence & 57 & $(24.5)$ \\
\hline Psychological violence & 18 & $(7.7)$ \\
\hline Money related violence & 14 & $(8.5)$ \\
\hline \multicolumn{3}{|l|}{ Relationship with perpetrators } \\
\hline Intimate partner & 121 & $(73.8)$ \\
\hline Family members & 32 & $(19.5)$ \\
\hline Relatives & 27 & $(16.5)$ \\
\hline Employer/boss & 15 & $(9.1)$ \\
\hline Friends & 16 & $(9.8)$ \\
\hline Acquaintance & 25 & $(15.2)$ \\
\hline Strangers & 47 & $(28.7)$ \\
\hline
\end{tabular}

Note: Multiple responses were allowed.

Table 4 Readiness of care for GBV survivors at health facility $(n=233)$ 
Readiness for care on survivors at health facility Number Percentage

\begin{tabular}{lccc}
\hline Guideline & Yes & 9 & $(3.9)$ \\
\hline & No & 224 & $(96.1)$ \\
\hline Medicines & Yes & & \\
\hline & No & 130 & $(55.8)$ \\
\hline Trained and skilled staff & 103 & $(44.2)$ \\
\hline Yes & & \\
\hline No & 21 & $(9.0)$ \\
\hline Trained medico-social worker & 212 & $(91.0)$ \\
\hline Yes & & \\
\hline No & 29 & $(12.4)$ \\
\hline No & 204 & $(97.6)$ \\
\hline Counseling room & & $(95.7)$ \\
\hline
\end{tabular}

Figures 


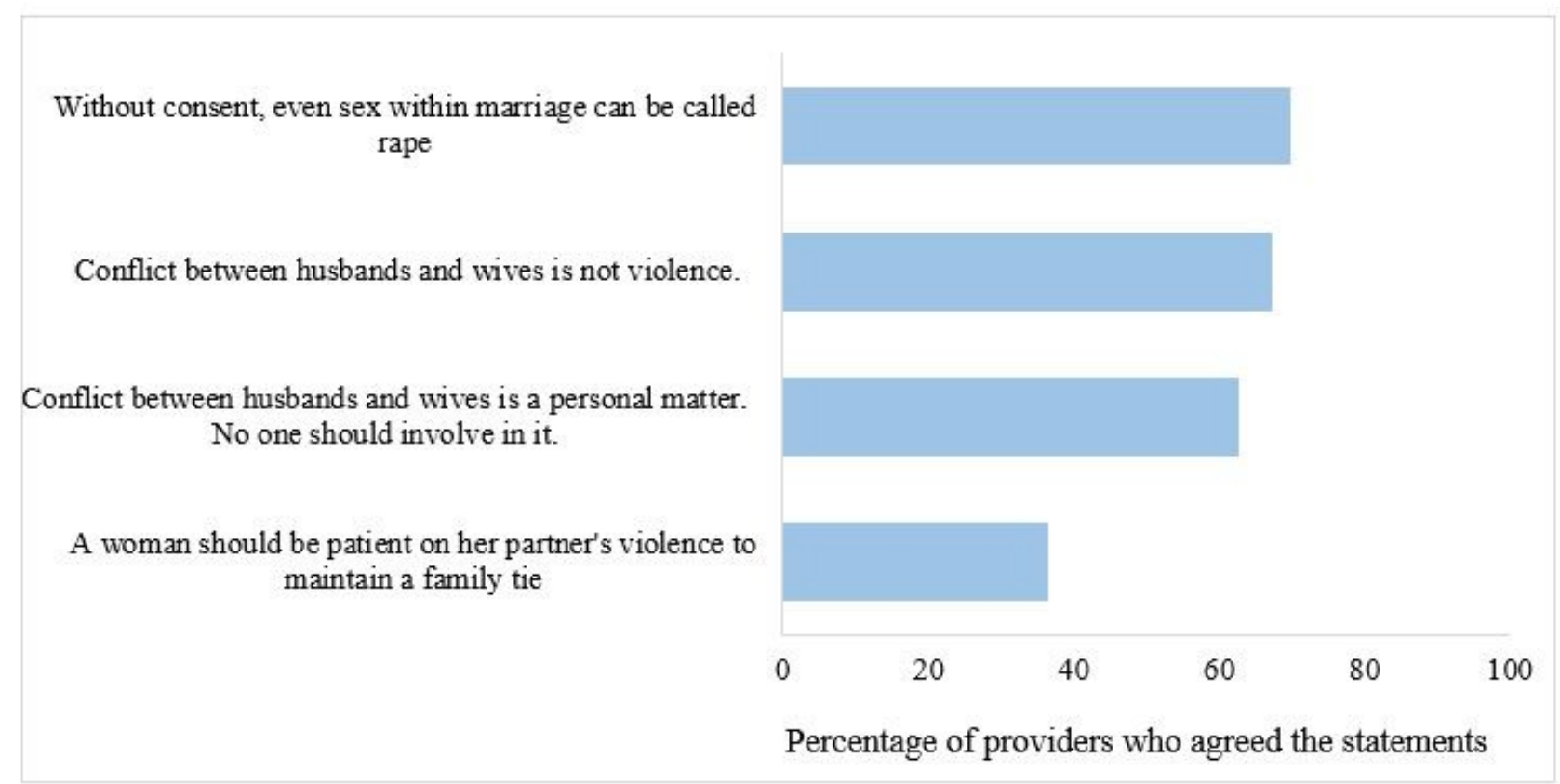

\section{Figure 1}

Perception of healthcare providers on IPV

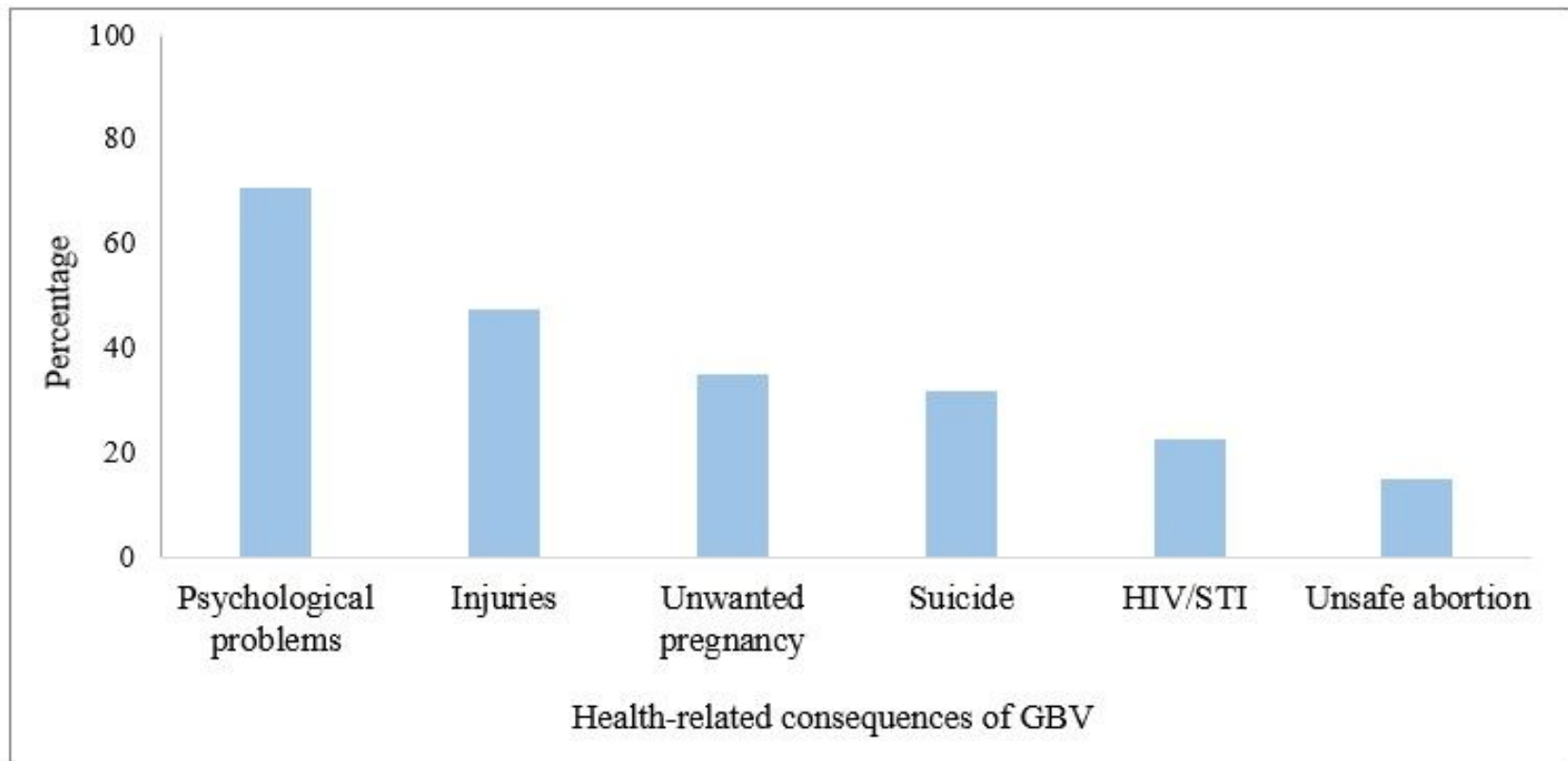

Figure 2

Healthcare providers' knowledge regarding health-related consequences of GBV 


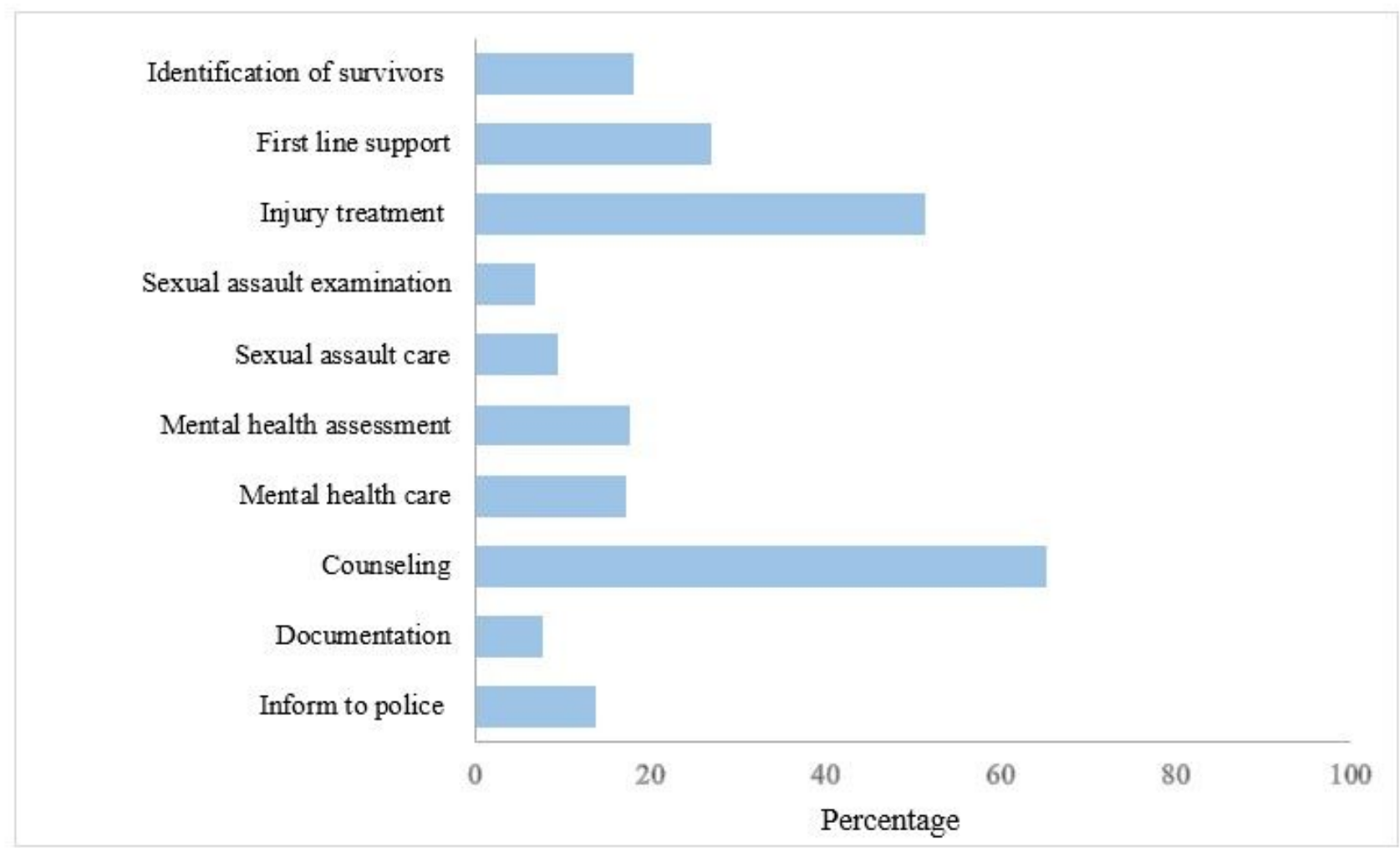

\section{Figure 3}

Healthcare providers' knowledge regarding components of GBV management 


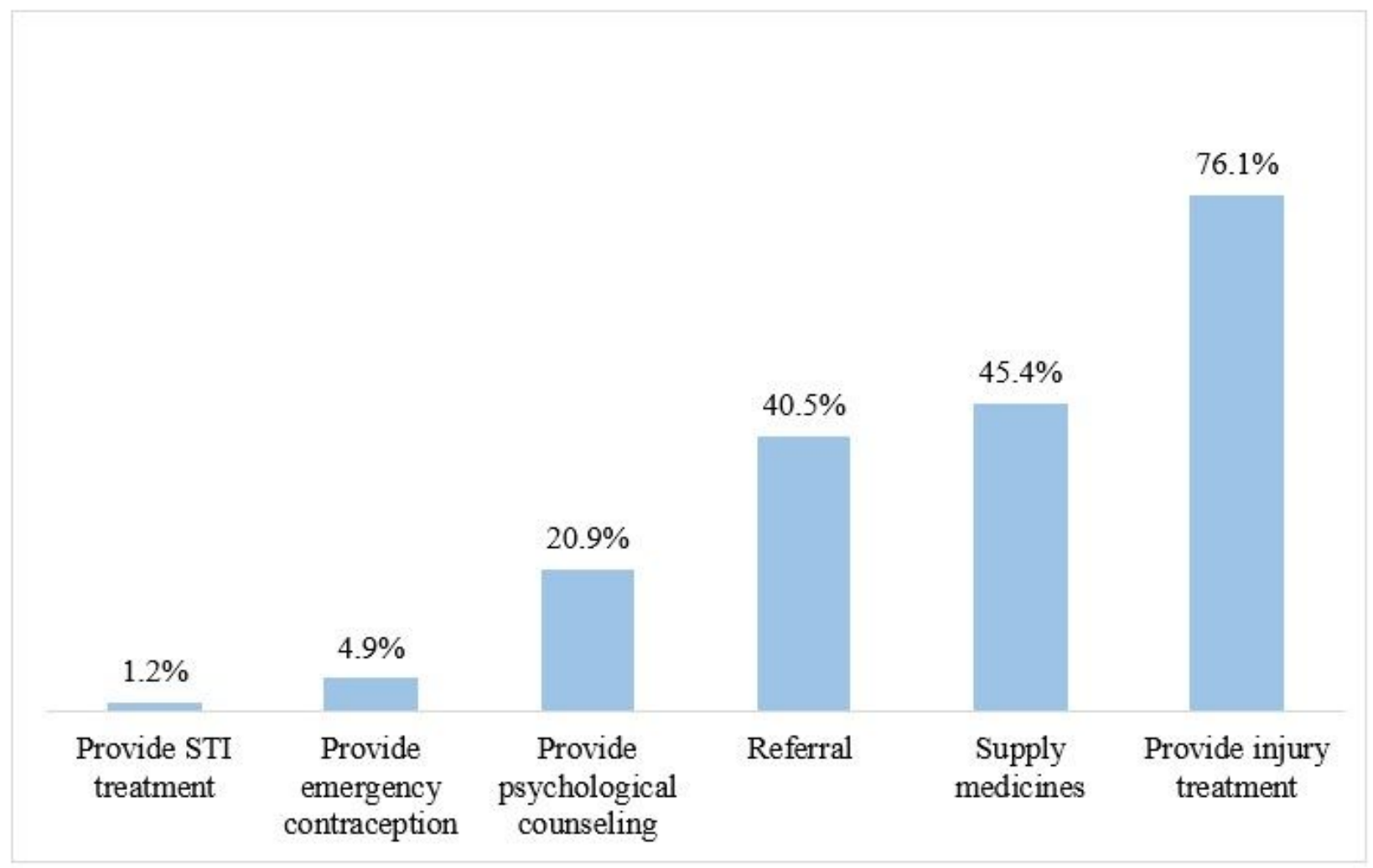

Figure 4

Care provided to GBV survivors by healthcare providers 